\title{
APRECIAÇÃO ERGONÔMICA DE UMA PORTARIA DE EDIFÍCIO
} MULTIFAMILIAR

\author{
PEIXOTO, Angélika (1) \\ SOARES, Fabiano Ribeiro (2) \\ ACIOLI, Patrícia Barbosa (3) \\ (1) UFPE, Mestranda em Ergonomia \\ e-mail: akpeixoto@yahoo.com.br \\ (2) UFMA, Mestrando em Ergonomia \\ e-mail: genesislab@live.com \\ (3) UFPE, Mestranda em Ergonomia \\ e-mail: patriciacioli@gmail.com.br
}

\begin{abstract}
RESUMO
Diante do aumento da criminalidade e da insegurança urbana, a pesquisa apresenta a apreciação ergonômica de uma portaria de um edifício multifamiliar, localizado na Avenida Boa Viagem, zona sul da cidade do Recife/PE. Visa: conhecer os principais elementos do ambiente físico (portaria) que influenciam o trabalhador; de que forma é possível usar as variáveis espaciais para se obter maior segurança, conforto e qualidade na realização das tarefas ; compreender e contribuir com indicações e sugestões para proporcionar melhores condições de trabalho ao porteiro (vigilante), para garantir um aumento na segurança dos usuários e da área ao redor.
\end{abstract}

Palavras chave: Análise Ergonômica; Portaria; Segurança.

\begin{abstract}
Faced with increased criminality and urban insecurity, the research presents the ergonomic appreciation of a security cabin of a multi-family building, located on Boa Viagem Avenue, south zone of the city of Recife / PE. This work aims to: $k$ now the main el ements of the physical environment (porter's area) that influence the employee; In what way it is possible to use the space variables to obtain greater security, comfort and quality in the accomplishment of the task s; Understand and contribute with indications and suggestions to provide better work ing conditions to the janitor and to ensure more safety conditions to users and the surrounding area.
\end{abstract}

Keywords: Ergonomic Analysis; Porter's Cabin; Safety. 


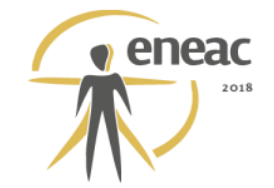

\section{INTRODUÇÃO}

O presente trabalho foi motivado pelo aumento da ocorrência de crimes, pela crescente insegurança nas grandes cidades e a necessidade de pesquisar e encontrar soluções físicas que colaborem para a melhoria do posto de trabalho que pode mudar tal situação. Apresenta como tema as relações entre ergonomia do ambiente construído e segurança, destacando as interfaces entre o posto de trabalho, nomeado de guarita (portaria) de edifício residencial multifamiliar, os trabalhadores (porteiros), os moradores, os transeuntes e a rua, bem como, aspectos que podem facilitar ou dificultar a vigilância do espaço, influenciando diretamente na sensação de insegurança e na ocorrência de atos criminais.

As guaritas (portarias) são consideradas importantes dispositivos de segurança, dessa forma é fundamental que o ambiente seja adequado para oferecer condições que contribuam para a eficiência, desempenho das funções, e conforto dos vigilantes (porteiros) para longas jornadas de trabalho, a fim de evitar possíveis invasões que possam pôr em risco a segurança dos moradores, assim como danos à edificação ou roubo de bens e equipamentos.

Considera-se que o posto de trabalho guarita, que tem por finalidade prezar pela integridade física de pessoas e patrimônio de um determinado sistema (empresas, universidades, residências etc.), se for ergonomicamente projetado pode ser utilizado para produzir efeitos comportamentais que diminuam o medo nos indivíduos e reduzam a ocorrência de certos tipos de atos criminais, ou seja, dispositivos que permitem maior vigilância e controle podem desencorajar o crime e comportamentos indesejáveis.

Este trabalho tem por objetivo iniciar uma pesquisa de análise ergonômica de guaritas, investigando as potencialidades e fragilidades presentes no posto de trabalho. Pretende-se também, averiguar como o design deste dispositivo de vigilância e controle pode ser utilizado de maneira mais eficaz na prevenção e combate à criminalidade.

A unidade de posto de trabalho escolhida para a realização do estudo fica na orla de Boa Viagem, zona Sul da cidade do Recife, e foi selecionada para servir como estudo de caso para o referente trabalho. A escolha é justificada por ser considerado o trecho mais nobre da cidade, ou seja, com maior capacidade de investir em segurança privada, por apresentar uma variada tipologia de guaritas e por ser apontada como uma área de interesse dos criminosos, vulnerável e insegura.

A pesquisa se embasa principalmente nos conceitos e aplicações da Ergonomia (MORAES \& MONT'ALVÃO, 2000) e no método científico Análise Ergonômica do Trabalho (IIDA 2008), com o intuito de reunir dados essenciais que permitam, ao final do estudo, recomendações de intervenções no ambiente físico, e que ofereçam maior segurança a seus usuários e arredores, considerado fator fundamental na qualidade de vida do cidadão.

\section{JUSTIFICATIVA}

O clima de insegurança predominante nas principais cidades, o elevado potencial de construção e, consequentemente, a verticalização das construções, aliados a um planejamento urbano inadequado, tem isolado os moradores em seus apartamentos cada vez mais afastados das ruas, transformando os espaços públicos em ambientes vulneráveis e favoráveis à atividade criminosa.

De acordo com dados da Secretaria de Defesa Social (SDS) de Pernambuco, demonstrados na figura 1, a criminalidade com relação aos crimes violentos contra o patrimônio (CVP1) aumentou $73 \%$ nos últimos dois anos 1 . 
Figura 1 - Números de crimes violentos contra o patrimônio.

\section{CRIMES VIOLENTOS CONTRA O PATRIMÔNIO (CVP)}

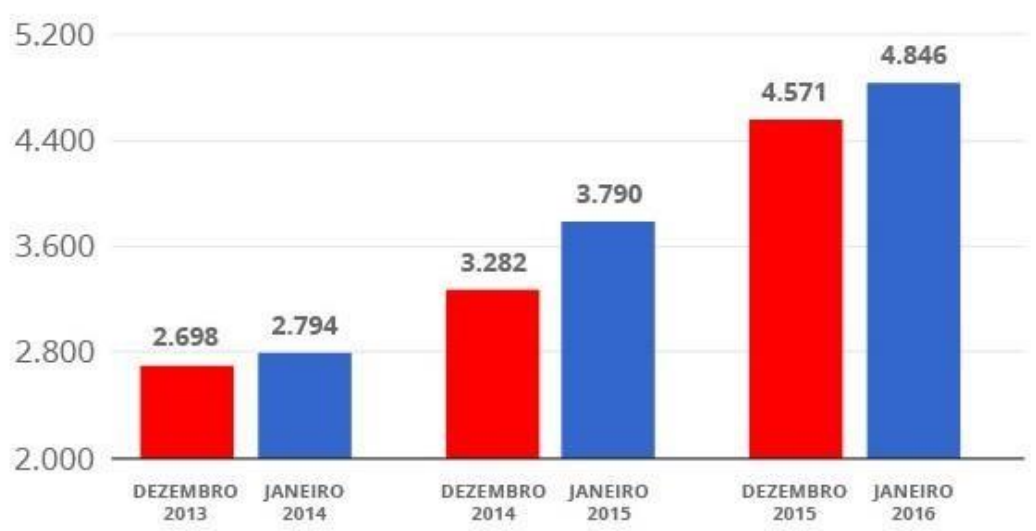

Fonte: Noticias NE10. Acesso em: 10 de abril de 2017.

Nesse contexto de aumento da violência, a paisagem urbana tem se modificado, principalmente nas últimas décadas, com inúmeras intervenções em relação à defesa do patrimônio pessoal e de propriedades. Atualmente existe uma tendência de projetar e construir segundo uma arquitetura urbana caracterizada pelo sentimento de insegurança e medo.

Contudo, o emprego da "arquitetura do medo", muito utilizada como medida preventiva de segurança pela maioria dos moradores, destacando-se os muros altos, as guaritas vistosas, portões eletrônicos, câmeras de vigilância e até mesmo cercas elétricas, vem afetando diretamente a configuração espacial urbana, isolando e aumentando o risco dos pedestres que circulam próximos a essas edificações.

Assim, Caldeira (2003) afirma que: "A nova estética da segurança decide a forma de cada tipo de construção, impondo uma lógica fundada na vigilância e na distância".

Um sistema de segurança privado é empregado com o objetivo principal de controlar, restringir, e monitorar o acesso de pessoas a uma determinada propriedade, focando a área de conexão do edifício com o sistema público imediato. Ou seja, os dispositivos de segurança empregados nas edificações visam defender e proteger a propriedade e seus usuários (internos à edificação).

Existem poucas pesquisas que abordam as relações entre as características físicas dos ambientes de guaritas e o desempenho das atividades dos porteiros em relação à segurança.

Sendo assim, faz-se necessário um estudo científico aprofundado do assunto, para tentar compreender e contribuir com indicações e sugestões para proporcionar melhores condições de trabalho ao porteiro, com o intuito de garantir um aumento na segurança da área ao redor.

\section{OBJETIVOS}

\subsection{Objetivo Geral}

O presente trabalho estabelece como objetivo geral a apreciação ergonômica de uma portaria (guarita) de uma edificação multifamiliar, localizada no bairro de Boa Viagem na cidade do Recife-PE. 


\subsection{Objetivos Específicos}

- $\quad$ Através da aplicação de ferramentas e instrumentos de análise ergonômica, qualificar e quantificar os custos humanos físicos, cognitivos e organizacionais;

- Investigar a postura e tarefa dos porteiros e as relações existentes entre os perfis espaciais e vulnerabilidade;

- $\quad$ Propor diretrizes para maior eficiência de vigilância e espaços mais seguros.

\section{MÉTODO}

A metodologia adotada utilizou diversos instrumentos, como a Análise Ergonômica do Trabalho, observação direta com registros fotográficos, e aplicação de questionários aos trabalhadores envolvidos, Check List de Couto, OWAS, RULA e a metodologia de intervenção ergonomizadora de Moraes e Mont'Alvão.

\section{DESCRIÇÃO E INVESTIGAÇÃO DA UNIDADE ESTUDADA}

O posto de trabalho analisado é uma portaria (Figura 2) de um edifício multifamiliar, localizado na Avenida Boa Viagem, zona sul da cidade do Recife/PE. O edifício foi construído em 1982 e por estar situado entre duas ruas, possui dois acessos (Av. Boa Viagem e Rua dos Navegantes), sua portaria já sofreu algumas reformas de melhorias e apresenta 7 trabalhadores no quadro de funcionários do condomínio.

Figura 2 - Portaria de Edifício Multifamiliar na Rua dos Navegantes (Recife/PE)

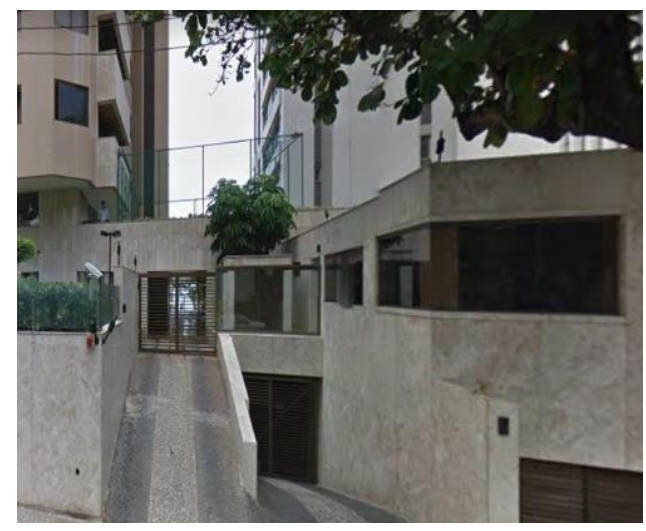

Fonte: Acervo dos autores, 2017.

\subsection{Descrição da Mão de Obra}

Através de entrevista foi possível obter os seguintes dados:

- $\quad$ Nível de instrução: ensino fundamental;

- $\quad$ Contrato de trabalho: CLT; 
Treinamento pela administradora do edifício;

- $\quad$ Escala de plantão: 12 por 36 horas;

- $\quad$ Absenteísmo pouco frequente;

- Férias por escala;

- $\quad$ Controle de ponto de frequência manual;

- $\quad$ Reside em casa de alvenaria na região metropolitana do Recife;

- Deslocamento por sistema público de transporte;

- $\quad$ Lazer aos finais de semana quando não está de plantão;

- Não possui assistência à saúde médica e odontológica particular.

\section{APRECIAÇÃO ERGONÔMICA DO SISTEMA HUMANO - TAREFA - MÁQUINA (SHTM) - PORTARIA DE EDIFÍCIO MULTIFAMILIAR}

\subsection{O Problema}

Apesar de ter sido um espaço pensado para otimizar as atividades do porteiro e garantir sua segurança, algumas questões como a inadequação do mobiliário ao trabalhador, que utiliza uma cadeira imprópria para a realização de suas tarefas; pouco espaço livre na bancada de trabalho; layout inadequado; claridade em excesso; podem acentuar problemas posturais, gerando uma série de desconfortos físicos. Ainda foram constatadas infiltrações nas esquadrias, que aumentam os riscos para sua saúde e segurança do trabalhador.

\subsection{O Sistema-alvo}

O objeto de pesquisa compreende apenas um posto de trabalho: a portaria de um edifício multifamiliar (Figura 3). É um ambiente utilizado por um funcionário em sistema de rodízio a cada doze horas (dois porteiros).

Figura 3 - Planta Baixa da portaria.
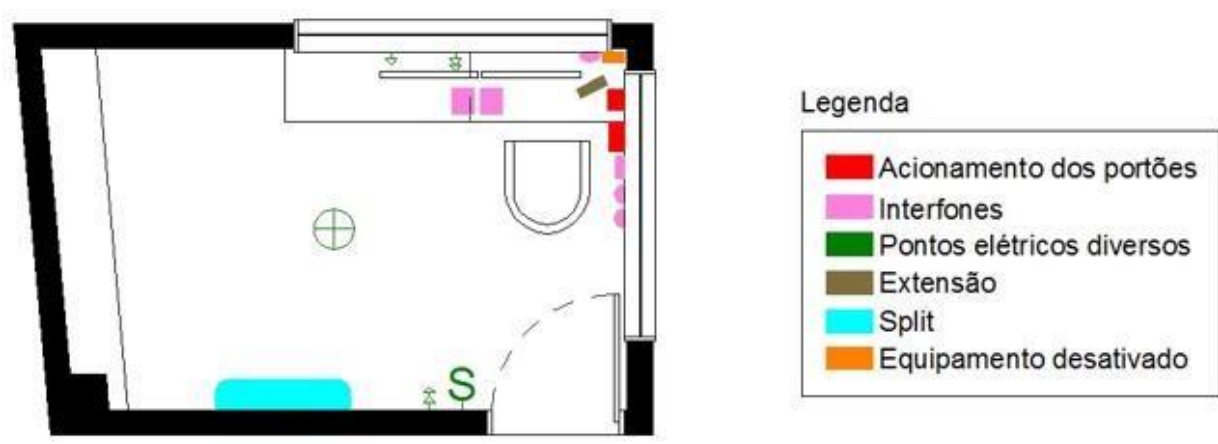

Planta Baixa Guarita

Fonte: Desenhada pelos autores, 2017. 


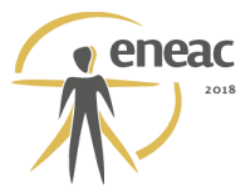

Figura 4 - Caracterização e posição serial do sistema

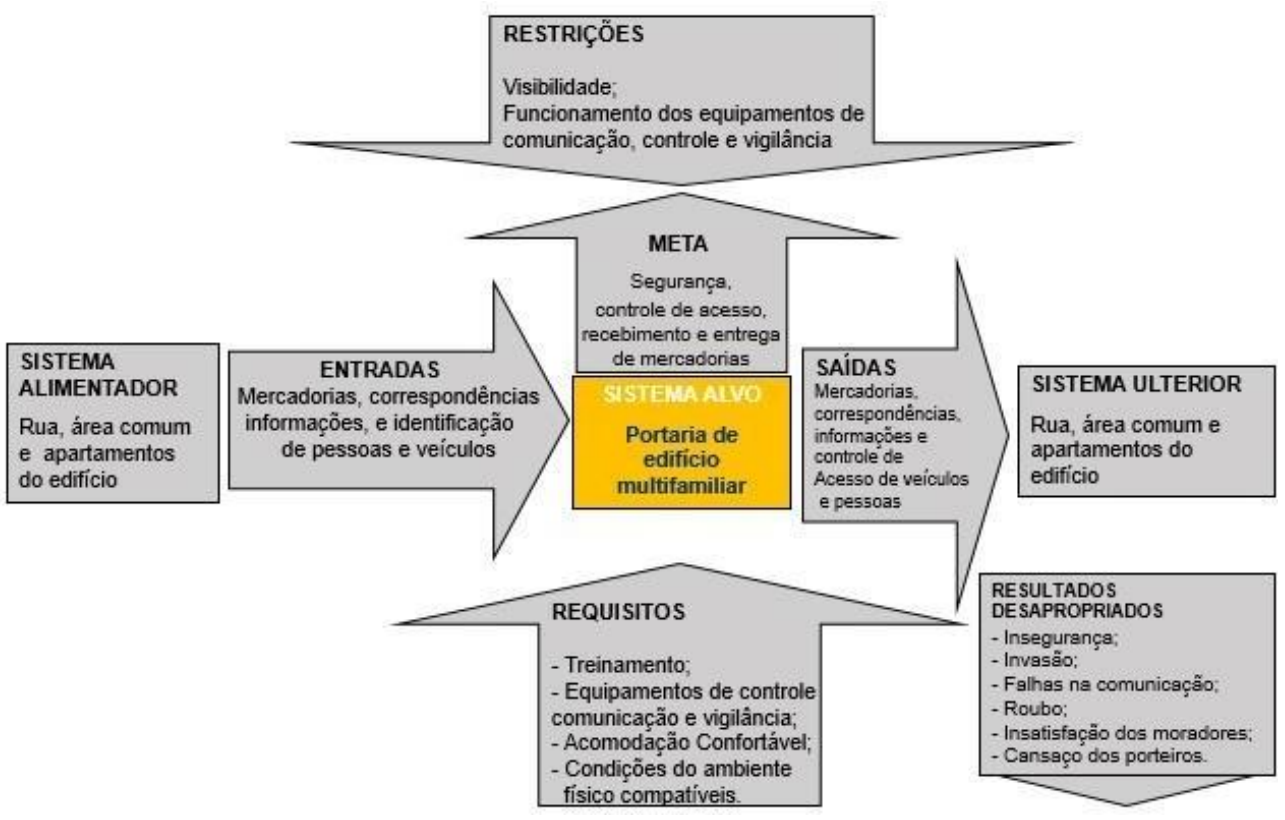

Fonte: Moraes e Mont'Alvão (2000), alterado pelos autores 2017.

Figuras 5 e 6 - Ordenação hierárquica do sistema e Expansão do sistema

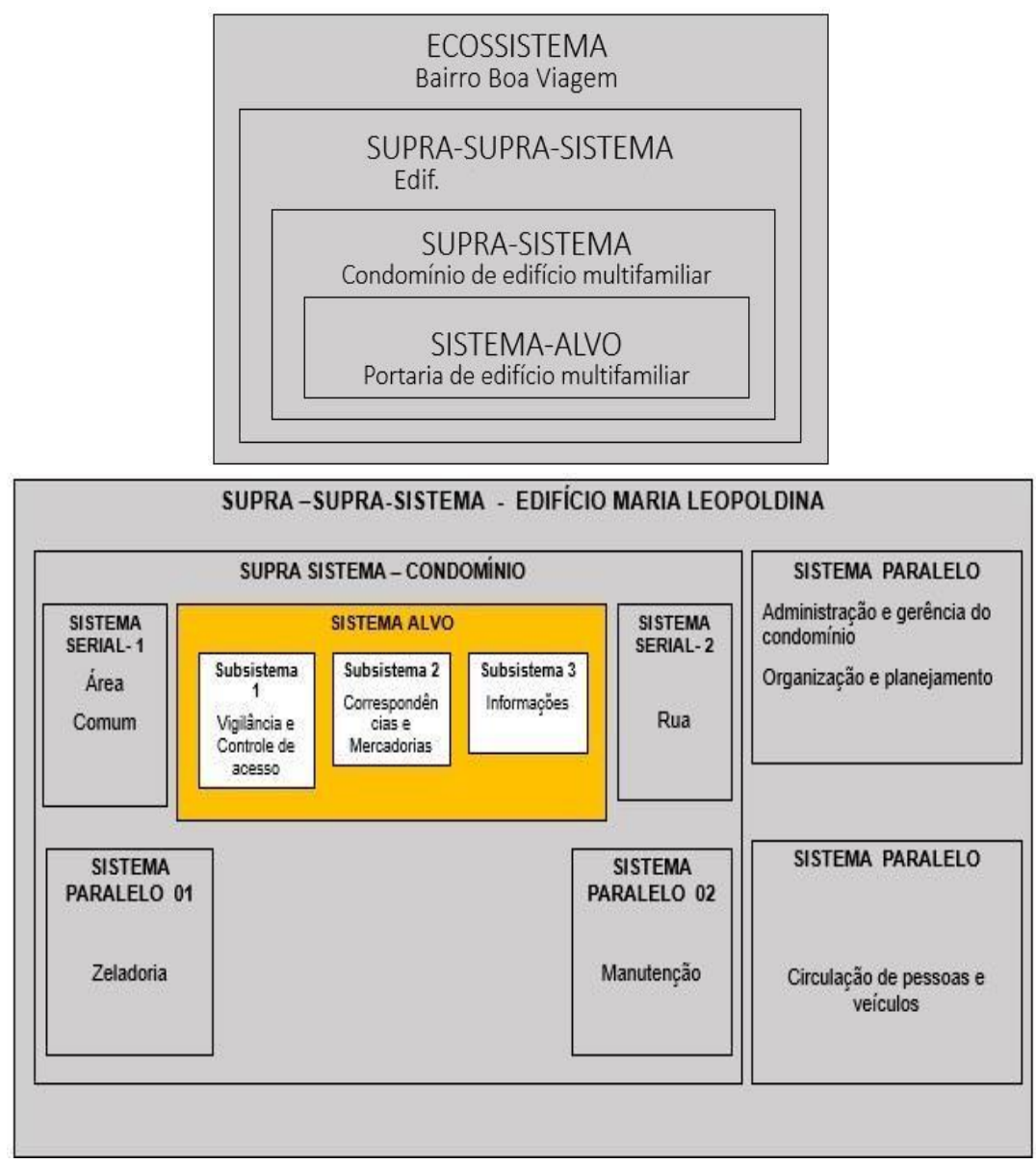

Fonte: Moraes e Mont'Alvão (2000), alterado pelos autores 2017. 
Figura 7- Modelagem comunicacional do sistema.
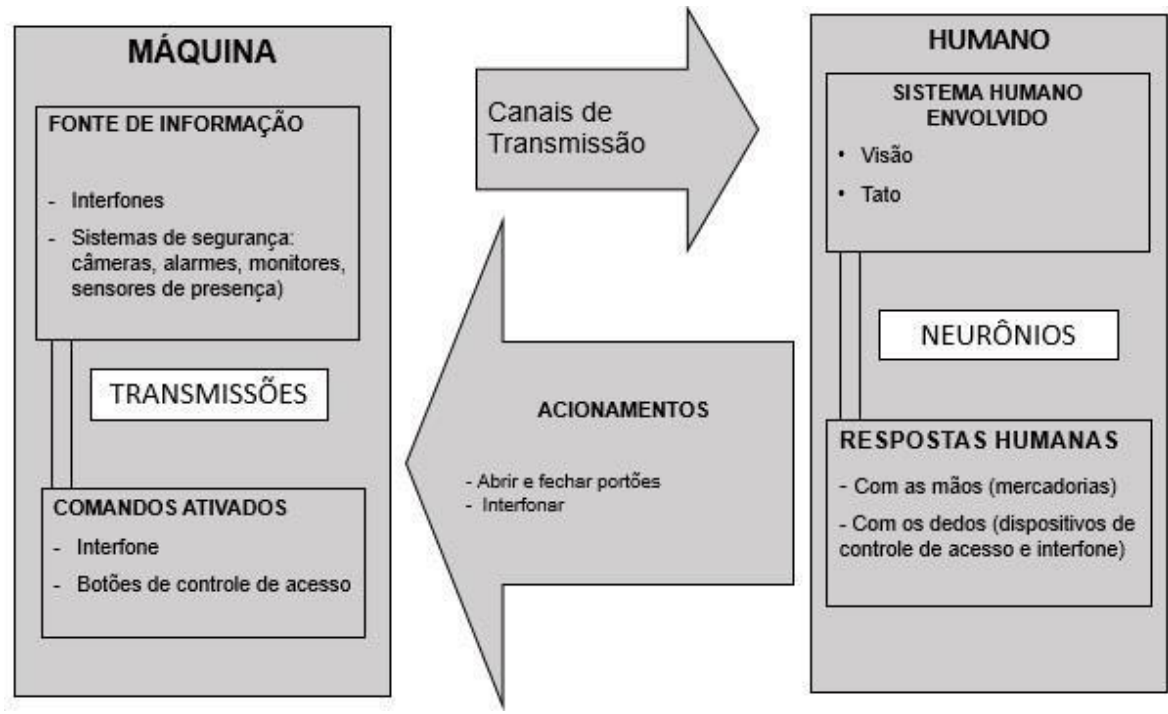

Fonte: Moraes e Mont'Alvão (2000), alterado pelos autores 2017

Figura 8 - Fluxograma funcional ação-decisão.

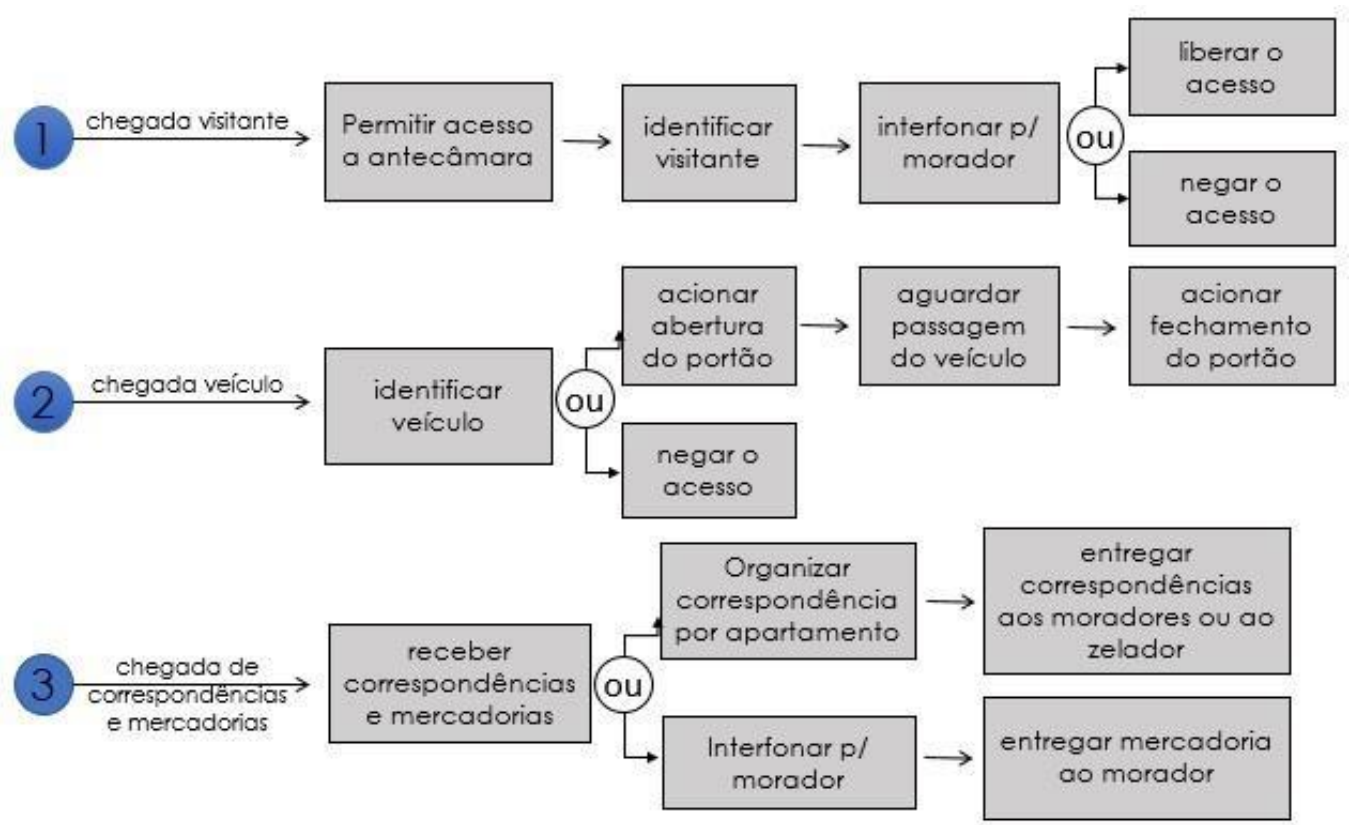

Fonte: Moraes e Mont'Alvão (2000), alterado pelos autores 2017.

\subsection{Problematização do SHTM}

- $\quad$ Problemas Interfaciais

A tarefa exige que o trabalhador permaneça a maior parte do tempo sentado (Figura 9). Devido à altura das janelas e falta de cadeira regulável (Figura 11), o porteiro trabalha em nível abaixo do adequado para a comunicação com os pedestres e visualização do ambiente (interno e externo). 


\section{eneac}

Figuras 9, 10 e 11 - Posto de trabalho do porteiro
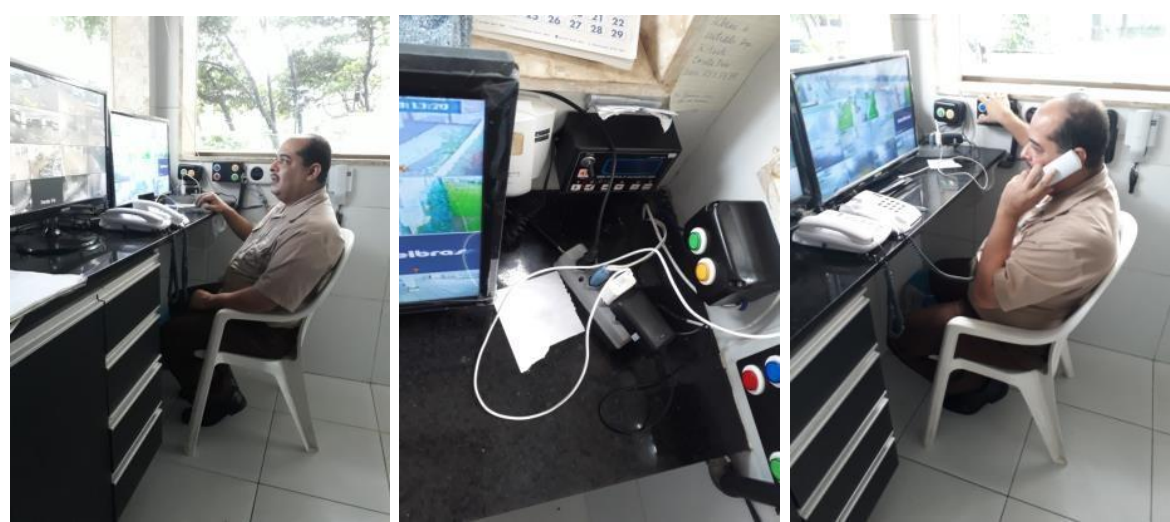

Fonte: Acervo dos autores (2017).

Envoltório acional com excesso de fios sobre a mesa de trabalho que já é estreita, com pouco espaço para movimento de mãos e braços do porteiro (Figura 10). Existem momentos em que o trabalhador exerce duas atividades simultaneamente, acionando portões de acesso de veículos e atendendo ao interfone (Figura 11). Existe desvio postural da coluna cervical e lombossacra, quando o trabalhador entra em contato com visitantes e muitas vezes no momento de acionar os botões dos portões de acesso.

- $\quad$ Problemas Interfaciais e Espaciais/Arquiteturais de Interiores

O porteiro tem que se curvar (Figuras 12 e 13) para pegar volumes acumulados no chão da guarita. Falta local apropriado para guardar mercadorias.

Figuras 12 e 13 - Espaço interno da portaria.

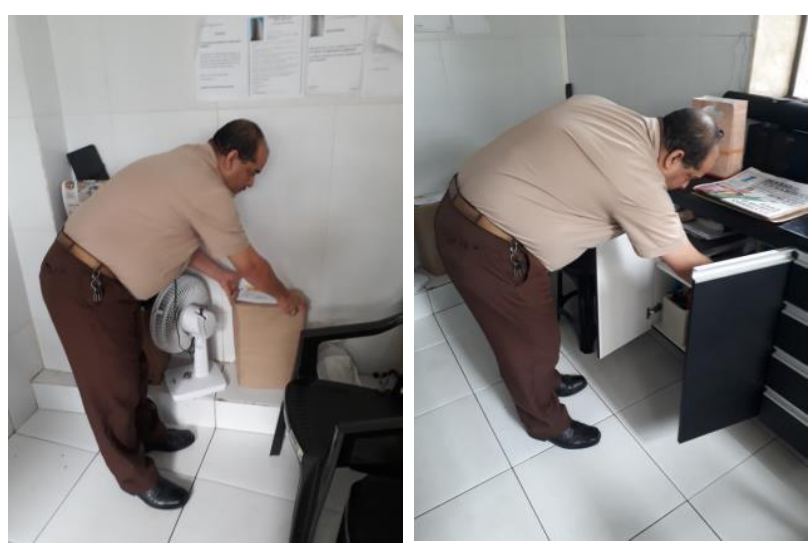

Fonte: Acervo dos autores (2017).

- $\quad$ Problema Instrumental

Além dos monitores que exibem imagens de várias câmeras, existem $\mathrm{m}$ uitos botões de acionamento dos portões de acesso para veículos e pedestres, de duas ruas, sem legenda, apenas com diferenciação nas cores (Figuras 14 e 15), exige uma exploração visual e boa memorização. 


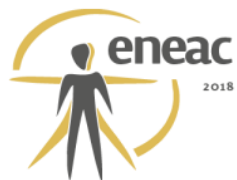

Figuras 14 e 15 - Botões de acionamento da portaria.

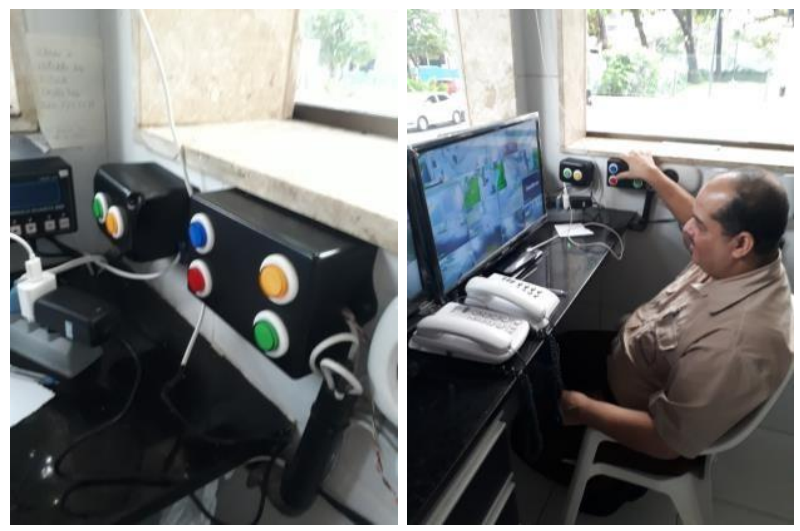

Fonte: Acervo dos autores (2017).

- $\quad$ Problema acidentário

Infiltração identificada na base da janela que fica por trás dos monitores do sistema de segurança, apontando risco de choque elétrico (Figuras 16 e 17).

Figuras 16 e 17 - Janela da portaria

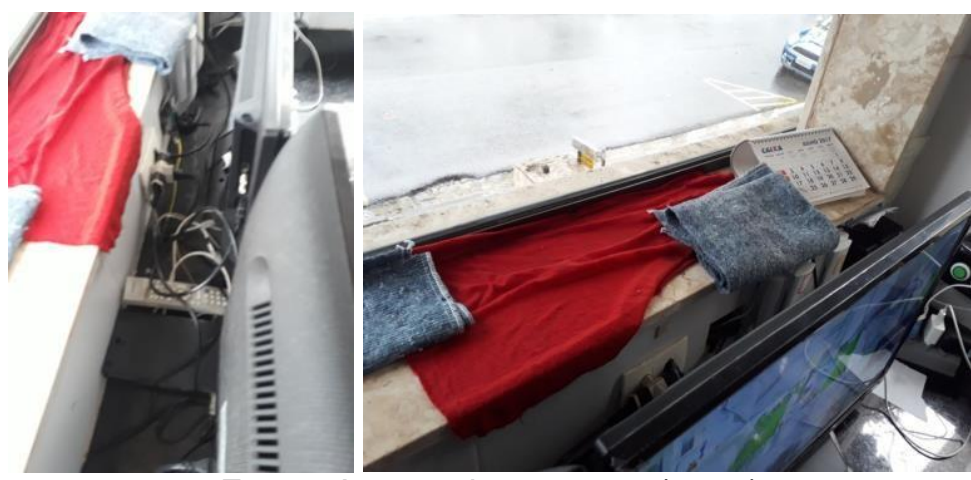

Fonte: Acervo dos autores (2017).

\subsection{Parecer ergonômico sobre o SHTM}

Figura 18 - Quadro de Formulação do problema e sugestões preliminares de melhoria.

\begin{tabular}{|c|c|c|c|c|c|c|c|}
\hline $\begin{array}{l}\text { CLA SSE DE } \\
\text { PROBLEMA }\end{array}$ & PROBLEMAS & REQUISITOS & $\begin{array}{l}\text { CONSTRA NGIMENTOS } \\
\text { DA TA REFA }\end{array}$ & $\begin{array}{l}\text { CUSTOS } \\
\text { HUMANOS DO } \\
\text { TRABAALHO }\end{array}$ & $\begin{array}{l}\text { DISFUNCCÖES DO } \\
\text { SISTEMA }\end{array}$ & $\begin{array}{l}\text { SUGE STOES PRELIMINA RES DE } \\
\text { MELHORIA }\end{array}$ & $\begin{array}{l}\text { RE STRICCOES DO } \\
\text { SISTEMA }\end{array}$ \\
\hline \multirow{5}{*}{ 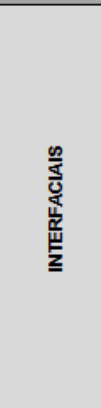 } & $\begin{array}{l}\text {-P Posição sentado } \\
\text { constante }\end{array}$ & $\begin{array}{l}\text { - Altemar posição } \\
\text { de pé/sentado }\end{array}$ & $\begin{array}{l}\text { - Postura inadequada } \\
\text { e desconfortável }\end{array}$ & $\begin{array}{l}\text { - Dores lombares } \\
\text { e nos membros } \\
\text { inferiores. }\end{array}$ & - Sonolência & $\begin{array}{l}\text { - Cadeira adequada e altemar } \\
\text { posição de pé/sentado }\end{array}$ & $\begin{array}{l}\text { - Negligência da } \\
\text { adm inistração }\end{array}$ \\
\hline & $\begin{array}{l}\text { - Rotação do } \\
\text { pescoço e flexão } \\
\text { frontaV̌cervical }\end{array}$ & $\begin{array}{l}- \text { Rever altura dos } \\
\text { monitores e } \\
\text { acesso visual das } \\
\text { janelas }\end{array}$ & \begin{tabular}{|l|} 
Trabalhador tem que \\
se esticar para ver 0 \\
movimento da rua
\end{tabular} & $\begin{array}{l}\text { - Dores nas } \\
\text { costas e pescoco }\end{array}$ & \begin{tabular}{|l} 
- Visibilidade \\
prejudicada \\
- Insegurança
\end{tabular} & \begin{tabular}{|l|} 
- Cadeira adequada e rever \\
posicionamento dos monitores
\end{tabular} & $\begin{array}{l}\text { - Negligência da } \\
\text { administraçấo }\end{array}$ \\
\hline & $\begin{array}{l}\text { - Barreira para } \\
\text { movimentos de } \\
\text { mãos e braços }\end{array}$ & $\begin{array}{l}\text { - Organizar fios e } \\
\text { relocar botôes e } \\
\text { interfones }\end{array}$ & $\begin{array}{l}\text { - Desviar dos fios para } \\
\text { alcançar botỗes de } \\
\text { acionamento }\end{array}$ & $\begin{array}{l}- \text { Dores membros } \\
\text { superiores }\end{array}$ & $\begin{array}{l}\text { - Possibilidade de } \\
\text { acionar botão errado }\end{array}$ & $\begin{array}{l}- \text { Organizar fios e relocar } \\
\text { equipamentos }\end{array}$ & $\begin{array}{l}\text { - Desinteresse e } \\
\text { negligência da } \\
\text { administracäa }\end{array}$ \\
\hline & $\begin{array}{l}\text { - Constrangimento } \\
\text { postural para } \\
\text { realizar atividades } \\
\text { sim ultaneamente } \\
\end{array}$ & $\begin{array}{l}\text { - Reorganizare } \\
\text { relocar } \\
\text { equipamentos }\end{array}$ & $\begin{array}{l}\text { O trabalhador tem } \\
\text { que alcancar dois } \\
\text { equipam entos ao } \\
\text { mesmo tempo } \\
\end{array}$ & $\begin{array}{l}\text { Estresse e } \\
\text { dores de cabeça }\end{array}$ & $\begin{array}{l}\text { - Dificuldade para } \\
\text { exercer funçốes } \\
\text { simultâneas }\end{array}$ & $\begin{array}{l}\text { - Relocar equipamentos, } \\
\text { reagrupar }\end{array}$ & $\begin{array}{l}\text { - Desinteresse da } \\
\text { adm inistração }\end{array}$ \\
\hline & - Torção de tronco & $\begin{array}{l}\text { - Facilitar } \\
\text { comunicação do } \\
\text { porteiro com os } \\
\text { visitantes }\end{array}$ & $\begin{array}{l}\text { - Torção lateral para } \\
\text { alcance de } \\
\text { equipam entos e } \\
\text { acionamento de } \\
\text { dispositivos }\end{array}$ & $\begin{array}{l}\text { - Dores œrvicais } \\
\text { e cansaço }\end{array}$ & $\begin{array}{l}\text { - Problemas de } \\
\text { comunicação }\end{array}$ & - Relocar equipamentos & $\begin{array}{l}- \text { Falta de } \\
\text { atualização da } \\
\text { adm inistração }\end{array}$ \\
\hline
\end{tabular}




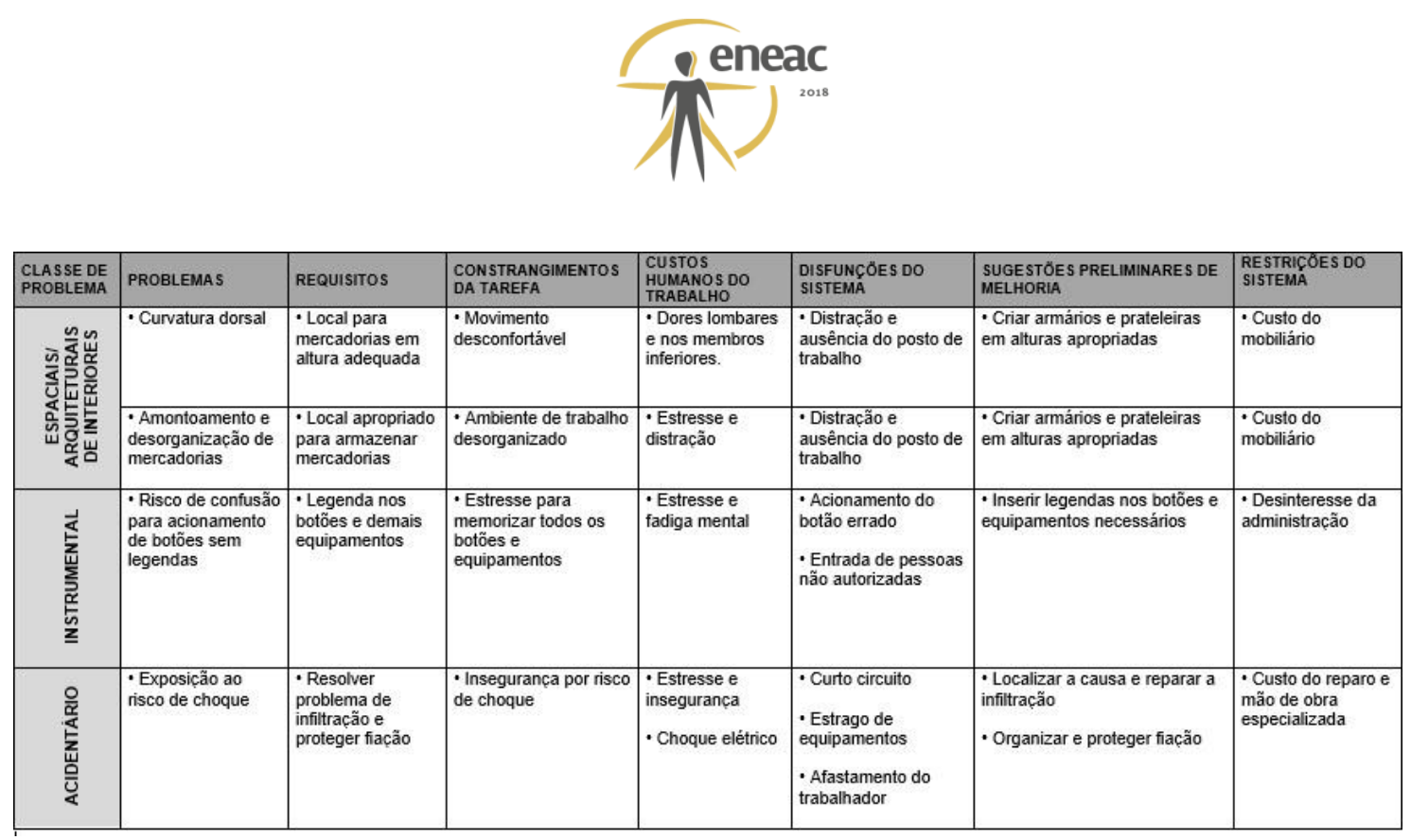

Fonte: Moraes e Mont'Alvão (2000), alterado pelos autores 2017.

\subsection{Diagnose ergonômica}

- $\quad$ Check List de Couto

O resultado do Check List de Couto nessa análise é de 17 pontos, correspondendo ao Risco Moderado.

\section{- $\quad$ Método OWAS}

O método de avaliação postural OWAS classifica as posturas em quatro categorias, onde a primeira trata da postura normal que dispensa maiores cuidados, exceto em casos excepcionais; a segunda categoria recomenda que a postura deverá ser verificada durante a próxima revisão de rotina de trabalho, sugerindo correções em um futuro próximo; a terceira recomenda que a postura deve merecer atenção com correções a curto prazo; e, por fim, a última categoria afirma que a postura avaliada merece atenção e correção imediata. 0 resultado da análise demonstra a atuação e os esforços durante a maior parte da jornada de trabalho do porteiro, quando o mesmo permanece sentado, ver figura 19 a seguir.

Figura 19 - Método OWAS.

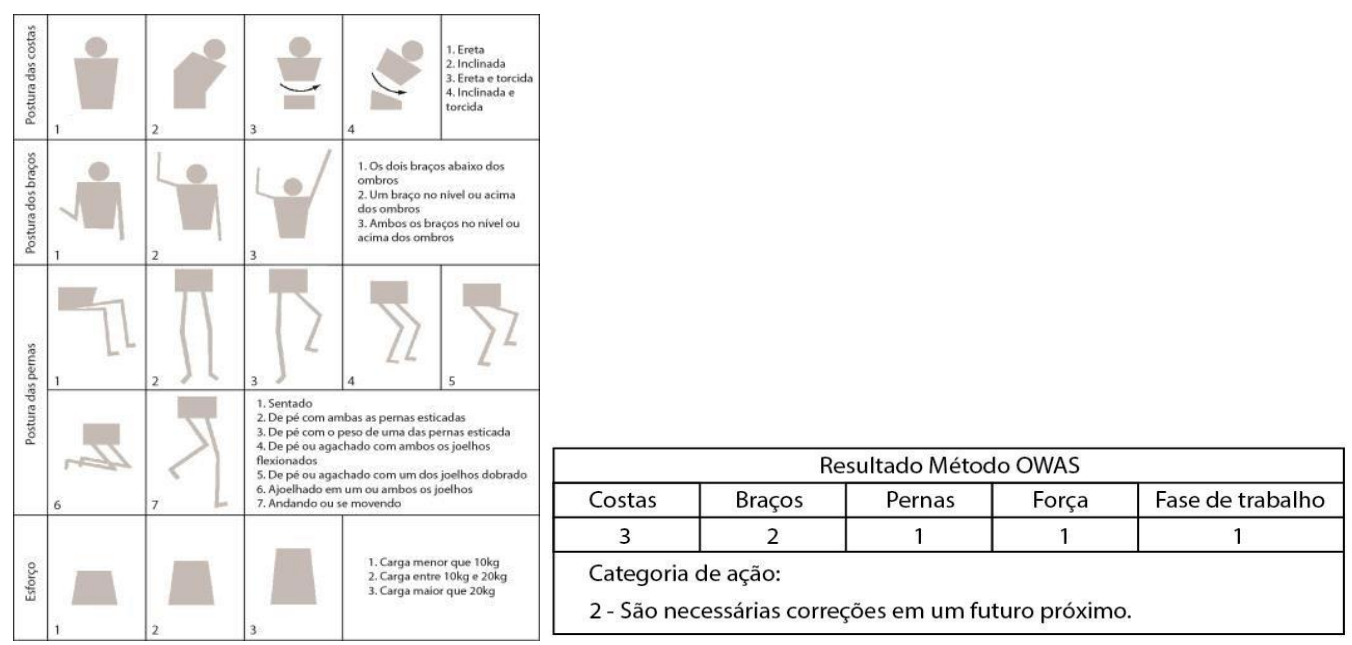

Fonte: lida (2008), redesenhado pelos autores em 2017. 


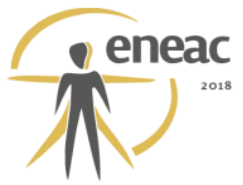

-

Método RULA

O método RULA foi desenvolvido por Lynn McAtamney e Nigel Corlett da Universidade de Nottingham em 1993, para avaliar a exposição dos trabalhadores a fatores de riscos que podem ocasionar transtornos nos membros superiores do corpo. Durante a aplicação do Método RULA, cada fator avaliado recebe uma pontuação (Figura 20).

Figura 20 - Resultado Método Rula.

\begin{tabular}{|c|c|l}
\hline PONTUAÇĀO & NIVELL DE AÇĀO & \multicolumn{1}{|c}{ INTERVENÇĀO } \\
\hline 1 ou 2 & 1 & Postura aceitável \\
\hline 3 ou 4 & 2 & $\begin{array}{l}\text { Deve-se realizar uma observação. } \\
\text { Podem ser necessárias mudanças. }\end{array}$ \\
\hline 5 ou 6 & 3 & $\begin{array}{l}\text { Deve-se realizar uma investigação. } \\
\text { Devem ser introduzidas mudanças. }\end{array}$ \\
\hline 7 & 4 & $\begin{array}{l}\text { Devem ser introduzidas mudanças } \\
\text { imediatamente. }\end{array}$ \\
\hline
\end{tabular}

Fonte: Software Ergolândia 6.0 http://www.fbfsistemas.com/ergonomia.html, acesso em julho de 2017.

A pontuação deve ser inserida em tabelas para que o resultado final do método seja encontrado (Figura 21)

\section{Figuras 21 e 22 - Tabela preenchida pelo método RULA e Resultado análise pelo método} RULA.
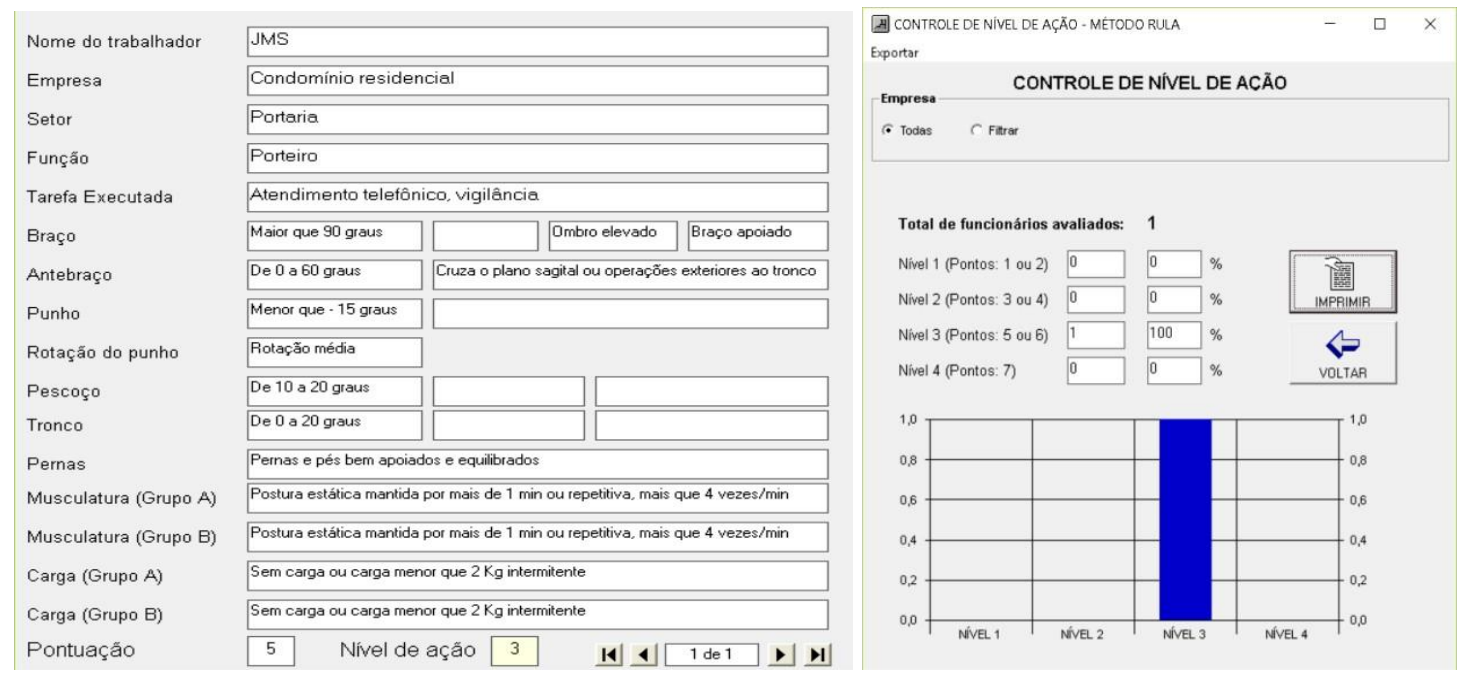

Fonte: Software Ergolândia 6.0 http://www.fbfsistemas.com/ergonomia.html, acesso em julho de 2017.

Como resultado apresenta nível de ação 3 , que segundo a tabela da figura 20 , indica a necessidade de investigação e introdução de mudanças. 


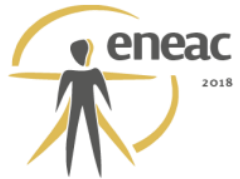

\section{CONSIDERAÇÕES FINAIS}

Neste trabalho, foram realizadas observações assistemáticas e análise postural da tarefa através de técnicas e métodos semiquantitativos para a obtenção de informações e apreciação ergonômica do posto de trabalho do porteiro de um edifício multifamiliar.

Para a diagnose ergonômica foram aplicados o Check List de Couto, que apontou risco moderado; o Método OWAS, apontando a necessidade de mudanças em um futuro próximo; e o Método RULA, onde foi identificado o nível de ação 3, apontando a necessidade de introdução de mudanças.

A metodologia utilizada com a problematização, sistematização e diagnose possibilitou a identificação e priorização dos problemas do sistema pesquisado (destacando a cadeira inapropriada para o usuário e a exposição ao risco de choque elétrico), e permitiu a elaboração de sugestões preliminares de intervenção e melhoria.

\section{REFERÊNCIAS BIBLIOGRÁFICAS}

CALDEIRA, T. P.do R. Cidade de muros: crime, segregação e cidadania em São Paulo. $2^{a}$ edição. São Paulo: Editora 34|Edusp, 2003.

GRANDJEAN, E. Manual de Ergonomia: adaptando o trabalho ao homem. $4^{\mathrm{a}}$ edição. Porto Alegre: Bookman, 1998.

IIDA. Itiro. Ergonomia: Projeto e Produção. $2^{\mathrm{a}}$ edição ver. e ampl. - São Paulo: Edgard Blücher, 2008.

MONT'ALVÃO, C.VILLAROUCO, V. Um novo olhar para o projeto: a ergonomia no ambiente construído. Teresópolis, RJ: 2AB, 2011.

MORAES, A.; MONT'ALVÃO, C. Ergonomia: conceitos e aplicações. $2^{a}$ edição ampliada. Rio de Janeiro: $2 A B, 2000$.

\section{REFERÊNCIAS ELETRÔNICAS}

$<$ http://noticias.ne10.uol.com.br/grande-recife/noticia/2016/03/09/numero-de-assaltos- cresce-nogrande-recife-e-assusta-populacao-601341.php> Acesso em: 10 de abril de 2017.

<http://fbfsistemas.com/ergonomia.html> Acesso em: 02 de julho de 2017. 